\title{
Sociality improves larval growth in the stag beetle Figulus binodulus (Coleoptera: Lucanidae)
}

\author{
HidEAKi MORI and SATOSHI CHIBA
}

\begin{abstract}
Department of Ecology and Evolutionary Biology, Graduate School of Life Sciences, University of Tohoku, Aobayama, Sendai, 980-8578, Japan; e-mail: hmori@jwrc.or.jp
\end{abstract}

Key words. Stag beetle, social behaviour, parental care, filial cannibalism, nestmate recognition, Lucanidae

\begin{abstract}
The benefits for offspring of attendant adult were investigated in the stag beetle Figulus binodulus. The initial growth rate of third-instar larva was significantly higher when the larvae were in a nest with adults compared to those in a nest without adults. The difference in growth rate is reflected in adult body size. Although the presence of adult beetle generally benefited the offspring, the adults did eat some of the larvae. Filial cannibalism was the primary cause of juvenile death in nests with adults. Mortality was lower in nests with adults related to the juveniles compared to nests with unrelated adults, suggesting that infanticide of nest mates may be inhibited. These results suggest that $F$. binodulus has a level of sociality and nest mate recognition that is very rare in stag beetles. Social behaviour may be more advantageous for small stag beetles than fighting.
\end{abstract}

\section{INTRODUCTION}

In many animal species, parental care is critical for the proper growth and development of their offspring (Clutton-Brock, 1991). Parents that invest in parental care positively influence the mass of their offspring (Moreno et al., 1997; Burness et al., 2001). Provisioning offspring with an energy-rich and/or high-quality diet improves their growth rate and reduces the duration of development, which increases offspring survival. Most young birds and mammals are for extended periods heavily dependent on parental provisioning or defence (Watanuki, 1992; Johnston, 1993; Rogowitz \& McClure, 1995; Oksanen et al., 1999). Although mainly a feature of mammals, parental care also occurs in insects.

Rigorous, dangerous and competitive environments are likely to induce parental care in various taxa of insects (Tallamy, 1984; Tallamy \& Wood, 1986). Severe environments may result in the evolution of parental care, especially in beetles (Hinton, 1981; Danks, 2002). Parental care occurs in at least 10 families, including Silphidae, Scarabaeidae, Passalidae, Scolytidae and Platypodidae. Previous studies indicate several key factors in the evolution of social behaviour, including parental care. (1) The food resource is either ephemeral, divisible, patchily distributed or occurs relatively infrequently (Bartlett \& Ashworth, 1988). (2) The nesting systems are relatively safe from predators, providing food, favourable temperature and humidity conditions, and the tunnels are easily barricaded (Scott, 1990). (3) It tends to occur in situations where finding and establishing a new nesting system may be difficult and dangerous (Kirkendall et al., 1997). For example, carrion beetles (Silphidae) and dung beetles (Scarabaeinae) generally use relatively ephemeral resources that they must protect against competitors and decomposers (Fetherston et al., 1990; Halffter, 1997). Passalid beetles (Passalidae) and bark beetles (Curculi- onidae) utilise food that remains available for a relatively long time but is difficult to digest (Kent \& Simpson, 1992; Schuster \& Schuster, 1997).

What, then, are the key factors that have led to the evolution of social behaviour in stag beetles? In the larval stage, stag beetles utilise decayed wood, which is difficult to digest (Robert \& Salansky, 1985; Araya, 1993). The larvae must break the hard wood with their mandibles since there are no adults present when the larvae hatch. Accordingly, most stag beetles have a long larval period (two to three years) during which there is a high mortality (Hayashi, 1987). If parents can improve the quality of the food available to the larvae then it is likely this will result in an increase in their growth rate and a decrease in mortality and duration of development.

The Asian stag beetle Figulus binodulus provides an excellent model for studying social behaviour in stag beetles. It is a xylophagous species, whose life cycle has many unique characteristics. $F$. binodulus is a small species $(9-12 \mathrm{~mm})$ and is not sexually dimorphic. The adult is carnivorous eating larvae and pupae of beetles (Araya \& Obuchi, 1993) and possibly termites found in decaying wood. Adults remain under the bark of dead trees, digging large numbers of tunnels and reproducing there. The adults pulverise the wood transforming it into a carpet of fine sawdust for their larvae (Araya et al., 1996). In the field, there is always extremely fine sawdust, almost like soil, around each beetles' nest in dead trees (Araya et al., 1996). Similarly, in the laboratory adults pulverise wood and produce fine sawdust prior to oviposition. The adults continue to crush wood during the period when their larvae are growing (H. Mori, pers. observ.). The hatchling larvae eat the sawdust and complete their development within only two to three months (Araya et al., 1996). This species spends most of it life in dead wood. Dispersal occurs only during the reproductive season, although the 


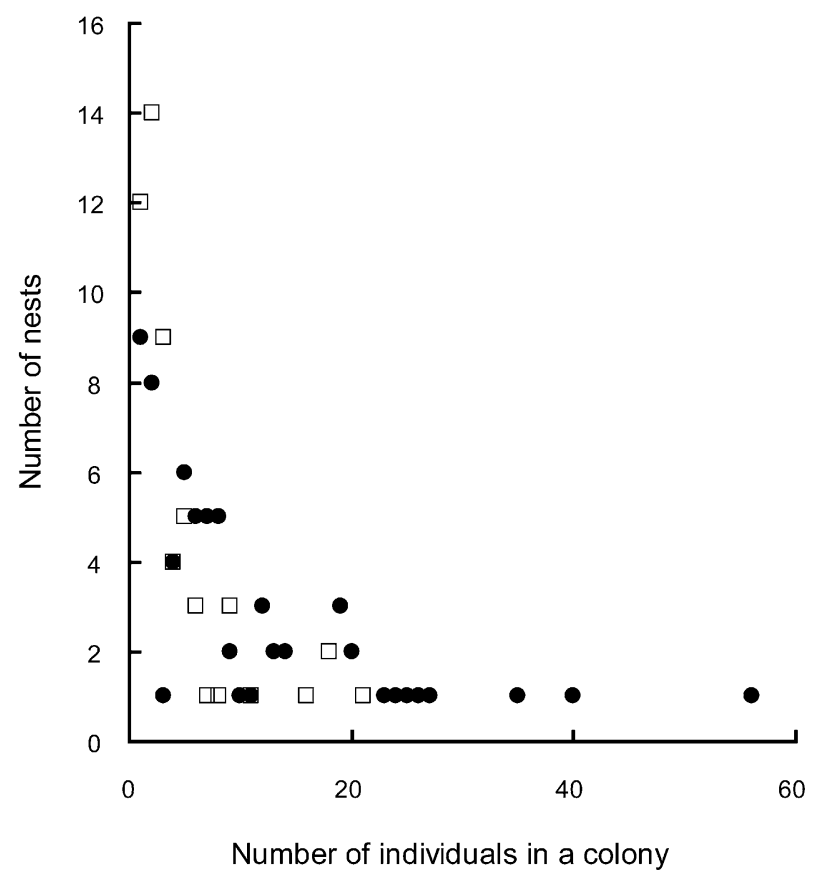

Fig. 1. Number of individuals in a colony early (June 2002 and 2004; $\mathrm{N}=60$, open square) and at the end of the reproductive season (March and October 2003; $\mathrm{N}=67$, filled circle).

details are unknown. Beetle associations are frequently observed during (at most 22 individuals, $\mathrm{N}=60$; Fig. 1) and after the reproductive season (at most 56 individuals, $\mathrm{N}=67$; Fig. 1).

Adult beetles and their larvae live together but the advantage of this association is completely unknown. The aim of this study is to show that social care occurs in this stag beetle. Here, we investigate the effects of the association with adults on the growth of the offspring in $F$. binodulus. In addition, whether adult beetles can recognize nest mates was determined.

\section{METHODS}

\section{Sample collection and preparation}

Adults of $F$. binodulus were collected from Hachijoujima Island, which is the most southernly of the Izu islands $\left(33.13^{\circ} \mathrm{N}\right.$, $\left.139.74^{\circ} \mathrm{E}\right)$. Beetles were collected early in their reproductive season, 1-7 June 2002, and the $\log$ occupied by each adult recorded.

The beetles were each placed individually in a $1.5 \mathrm{ml}$ vial, which was then kept in the dark in an incubator maintained at 27 $\pm 1^{\circ} \mathrm{C}$ and a high humidity. Once a week the beetles were fed chopped mealworms. The beetles were induced to reproduce by placing an adult male and female in a nest dish (plastic Petri dish $=\varnothing 150 \mathrm{~mm} \times 5 \mathrm{~mm})$ with coarse pieces $(\varnothing 3-5 \mathrm{~mm})$ of decayed wood. Under these conditions, females started to oviposit in approximately two to three weeks, and the eggs took two weeks to hatch. These beetles and their offspring were used in the experiments.

\section{Experimental design}

Eleven experimental nests were established. Each nest contained ten larvae from the same nest dish and fresh, coarse pieces of decayed wood. Then four adult beetles were placed in each of seven of the nests ("Family" nests). The choice of four

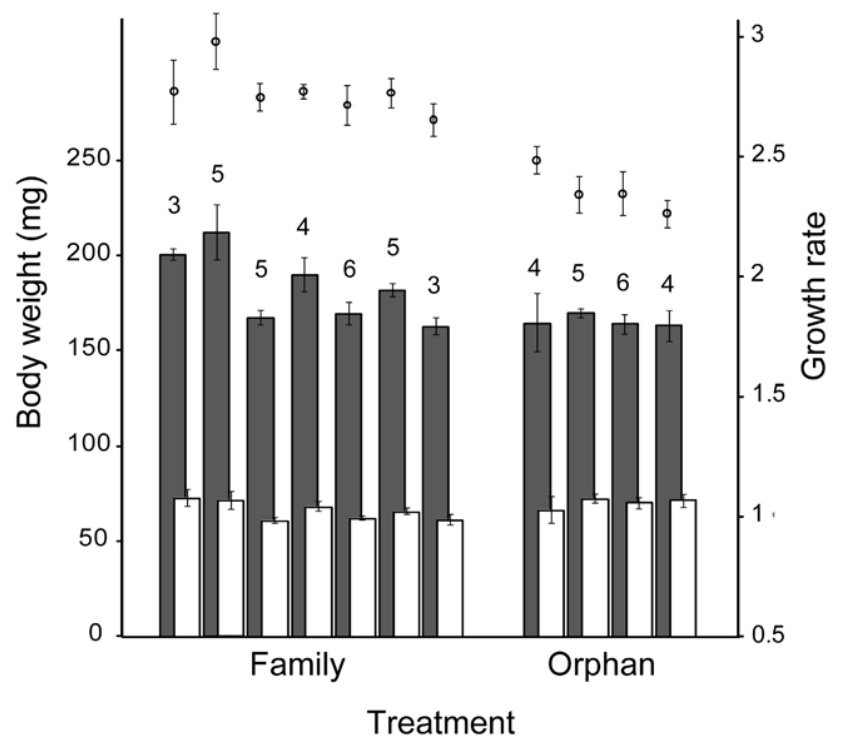

Fig. 2. Mean ( $\pm \mathrm{SE}$ ) weight of larvae at moulting (open bar) and on the seventh day after ecdysis (closed bar). These weights do not differ significantly between treatments (at moulting, linear mixed model $F(1,9)=3.509, P=0.0938$; and seven days later, linear mixed model $F(1,9)=3.610, P=0.0899)$. Open circles represent the growth rate $( \pm \mathrm{SE})$ of the larvae in each nest. The growth rate of third-instar larvae over the first seven days was significantly higher in Family nests than in Orphan nests (linear mixed model $F(1,9)=48.172, P=$ 0.0183 ). The number between each bar and circle indicates sample size.

adults reflects the mean number of adult beetles found in a log in the field (Mean $=4.4, \mathrm{~N}=60$; Fig. 1). The remaining four nests contained only larvae ("Orphan" nests). Adult beetles in the Family nests pulverised the wood but it is not food for them. They were fed chopped mealworms once a week outside of the nest.

To determine the effect of the association with adults the growth rate of the third-instar larvae was measured by recording their weight on the day they moulted to the third instar, which is the last moult and easy to recognize, and again seven days later. The growth rates (weight on the seventh day/ weight on the first day) of the larvae in the Family nests were compared with those of the larvae in the Orphan nests. The other measurement collected was the final body size of the offspring. At emergence the total length of the beetles, excluding mandibles, was measured.

The viability and condition of the larvae and adults were checked daily. Because larvae have a transparent cuticle their gut can be seen from outside the larval body and used to estimate their state of hunger. The condition of the gut and growth rates were used to determine the cause of death of larvae. For example, if the gut was empty for a long period and the body weight gradually decreased, we concluded that the larva died of malnutrition.

The results of different Family treatments were compared to determine whether beetles recognize nest mates. There were two types of Family nests. Three "Relative" nests, in which the adults were from the same log including the parents of the larvae, and four "Foster" nests, in which the adults came from different logs (unrelated). Filial cannibalism is the main cause of death in Family nests (H. Mori, pers. observ.). This means that survival depends on the frequency of filial cannibalism. As the larvae that died were quickly removed, it is possible to deter- 


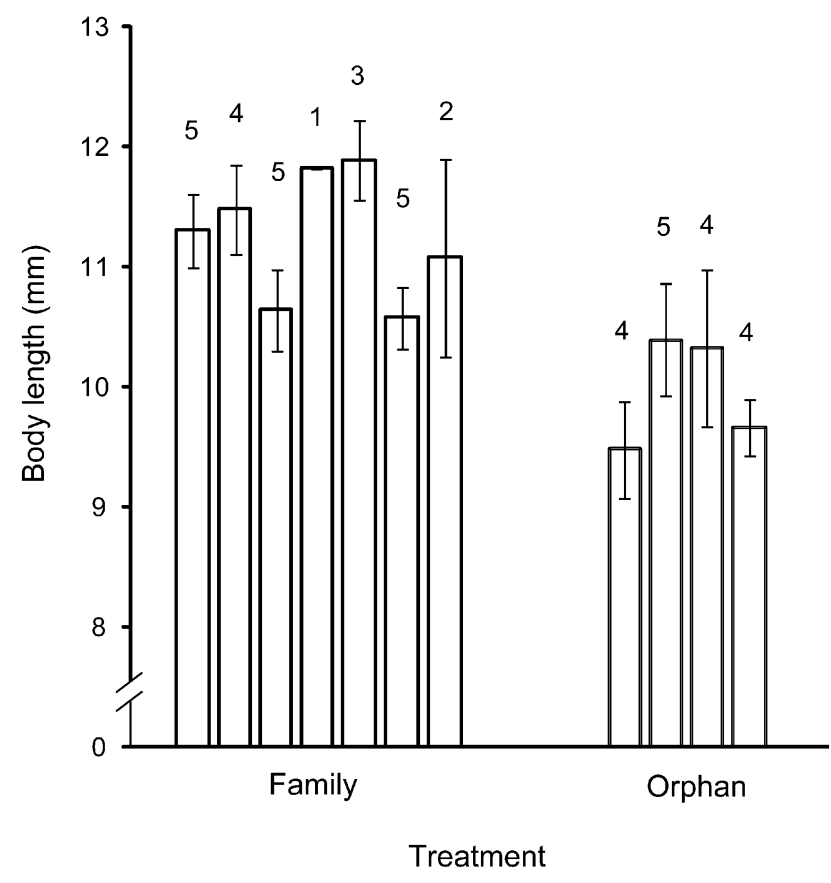

Fig. 3. Mean ( \pm SE) length of newly emerged adults. Each bar represents an experimental nest. The adults that developed in nests with adults (Family nest) were significantly larger than those that developed in nests without adults (Orphan nest) (linear mixed model $F(1,9)=13.924, P=0.0047)$. Above each bar is the size of the sample.

mine whether they died because of cannibalism or necrophagy. Comparison of the results for the two types of Family nests was used to determine whether survival was dependent on the relatedness of the adults.

All statistical analyses were done using software package $\mathrm{R}$ (R Development Core Team, 2005). Growth rate and body size were analysed using the linear mixed model in the nlme package (Pinheiro \& Bates, 2002). Nest was included as a random effect. The binominal results for dead or live larvae were analysed using a generalised linear mixed-effects model (GLMM) in the R package "Ime4" (Bates, 2008). Nest was entered as a random term.

\section{RESULTS}

The growth rate of the third-instar larvae in the Family nests was significantly higher than in the Orphan nests $(F$ $(1,9)=48.172, P=0.0183$; Fig. 2$)$. However, the initial weights of the larvae $(F(1,9)=3.509, P=0.0938$; Fig. $2)$ and their weights after seven days $(F(1,9)=3.610, P$ $=0.0899$; Fig. 2$)$ did not differ between treatments. The larvae kept with adult beetles were more developed in their emerged size than those that were reared without adults, that is, in the Orphan nests $(F(1,9)=13.924 P=$ 0.0047; Fig. 3).

In Family nests filial cannibalism was observed on eight occasions. Confirmed cannibalism accounted for $20.5 \%$ of total deaths in Family nests. However, the most frequent cause of death was sudden disappearance, most likely due to cannibalism. Thus, of the deaths a maximum of $92.3 \%$ is attributed to cannibalism. The comparison of the survival between groups showed that significantly more juveniles survived in the Relative nests than in

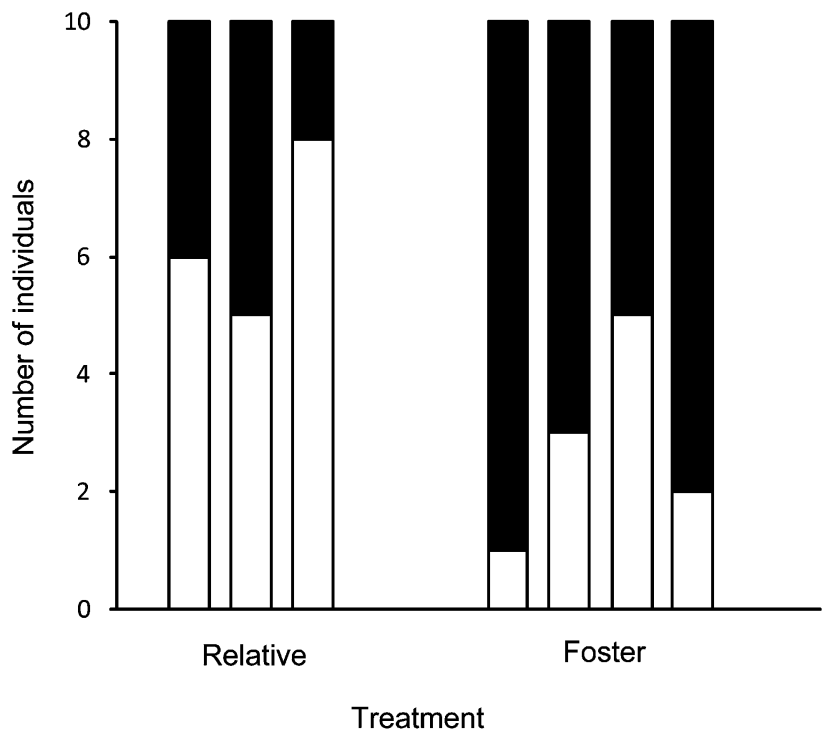

Fig. 4. Survival of larvae in Relative and Foster nests. Each bar represents an experimental nest and indicates how many of the ten larvae survived (open bar) and how many died (closed bar). The survival of the larvae in the Relative nests was better than in the Foster nests (generalised linear mixed model $Z=$ $-2.923, P=0.0035)$.

Foster nests (generalised linear mixed model $Z=-2.923$ $P=0.0035$; Fig. 4). More than $40.0 \%$ of the larvae in Orphan nests died of malnutrition, as their guts appeared empty for more than a week prior to death and their body size gradually decreased.

\section{DISCUSSION}

These results suggest that association with adults improves juvenile growth in F. binodulus. Adult association should subsequently affect the fitness of the beetle, as the third-instar is the final and longest larval stage (Araya et al., 1996) and the one that shows the greatest gain in mass. This was reflected in the differences in the sizes of the adults at emergence. A large body weight indicates the larvae had a good supply of food and that to be large adult is likely to be successful in acquiring food.

The most plausible cause of the improvement in juvenile growth in the presence of adults is that the adults improve the diet of the larvae. This hypothesis is supported by the finding that the majority of deaths in the orphan nests were caused by malnutrition, which suggests that it is difficult for larvae to produce their own food. The exact mechanism by which adult beetles improve the diet of juveniles remains unknown; the present findings suggest that for good growth and survival the larvae need the fine sawdust prepared by adult beetles. The mandibles of juvenile $F$. binodulus are narrower than those of other stag beetles, suggesting that the larvae of this species are not adept at pulverizing wood. In the reproductive season adults process wood and generate a carpet of fine sawdust, which we assume is easy for larvae to digest and sustains their healthy growth. 
Food improvement is one of the main features of social evolution in beetles. Carrion beetles prepare carcasses (Eggert et al., 1998), dung beetles form dung balls (Halffter et al., 1996) and bark beetles cultivate ambrosia fungi (Kirkendall et al., 1997). The discovery of sociality in $F$. binodulus provides further evidence for social evolution in beetles and is the latest example of sociality in stag beetles. Adults may also improve larval growth by manipulating food in other ways. The Passalid larvae require the nitrogen in the faeces of their parents for growth (Valenzuela-Gonzalez, 1992). Burying beetles provide their larvae with nutritional supplements via their regurgitations (Scott, 1998) and Passalid beetles via trophic eggs (Ento et al., 2008). Adult $F$. binodulus are carnivorous and therefore produce faeces rich in nutrition. Further observations are necessary to determine whether larvae of $F$. binodulus require nutritional supplements.

Although larvae increase their fitness by associating with adults, they risk attack from conspecifics. The most frequent cause of larval death is filial cannibalism, irrespective of whether they are with related or unrelated adults. Filial cannibalism frequently occurs in beetles (Trombo, 1990; King \& Fashing, 2007) and may serve to eliminate sick larvae and recycle precious nutrients (Crespi, 1992). The ability of adults to recognize kin is advantageous as killing their own larvae reduces their reproductive fitness. The difference in the frequency of filial cannibalism reported here suggests that there is less infanticide when adults associate with related larvae. These results raise the possibility of nest mate recognition. The filial cannibalism and nest mate recognition in $F$. binodulus resembles that in social spiders in which sociality is associated with a family group and extended maternal care. Although unrelated spiders are accepted by a group, cannibalism and some kin recognition occurs (Evans, 1999). In addition, communal breeding is often profitable even if group members are not kin. There are examples of unrelated helpers in birds and mammals (Riedman, 1982; Eadie et al., 1988; Meek \& Robertson, 1991; Kalmbach, 2006) and burying beetles prepare carcasses communally (Scott, 1997). The order of benefit obtained by larvae of $F$. binodulus from the association with adult beetles is likely to depend on the number of adults in a colony, which determines the amount of sawdust produced and the amount of energy expended by the adults. This hypothesis is supported by the findings that females often lay further eggs when the first generation pupates (H. Mori, pers. observ.), with the newly emerging first generation adults contributing to sawdust production. In this case the larvae coexist with related adults of two generations, and receive benefits not only from their parents but also from their older siblings. In the present study, however, relatedness within a nest is unknown. Future DNA analysis of nest mates will clarify whether or not families consist of relatives.

Many species of stag beetle are sexually dimorphic (Darwin, 1871; Clark, 1977; Otte \& Stayman, 1979; Kawano, 2000). Male stag beetles have large mandibles, which they use to fight with other males for females and limited resources (Mathieu, 1969; Hayashi, 1987; Okada \& Hasegawa, 2005; Harvey \& Gange, 2006). In contrast, $F$. binodulus has small mandibles, which are useful for pulverising wood, and is not sexually dimorphic. These characteristics are likely to have evolved because they improve offspring growth. Absence of sexual dimorphism, small mandibles and coexistence of larvae and adults in the same log are features of other small stag beetles, such as Figulus punctatus, Figulus boninensis and Nigidius lewisi (Araya et al., 1996). These findings suggest that cooperative and antagonistic behaviour are alternative strategies used by stag beetles competing for limited resources. Future studies on other species may uncover the cause of evolution of sociality in stag beetles.

ACKNOWLEDGEMENTS. We wish to thank J. Konuma, N. Wakayama, O. Miura and D. Miura for helpful advice and discussions. We also thank K. Kikuchi and T. Yamashita for their help with the sampling of $F$. binodulus. Comments from the editor I. Hodek and two anonymous reviewers improved the manuscript. This study was funded by grants from the Japan Society for the Promotion of Science.

\section{REFERENCES}

ARAYA K. 1993: Relationship between the decay types of dead wood and occurrence of lucanid beetles (Coleoptera: Lucanidae). Appl. Entomol. Zool. 28: 27-33.

Araya K. \& OBuchi T. 1993: Life histories of Japanese Lucanid beetles (Coleoptera: Lucanidae). IV. Figulus Maclay, 1819 (Part1). Insects \& Nature 28: 43-47 [in Japanese].

Araya K., Kon M. \& Ueda A. 1996: Sub-social system of xylophagous beetles. In Saito Y. (ed.): Evolutionary Biology of Parent-offspring Interaction. Hokkaido University Press, pp. 76-108 [in Japanese].

Bates D. 2008: The Lmer Package for R: Linear Mixed-effects Models Using S4 Classes, Version 0.99875-9. http://cran. rproject.org/web/packages/lme4/index.html.

Bartlett J. \& Ashworth C.M. 1988: Brood size and fitness in Nicrophorus vespilloides (Coleoptera: Silphidae). Behav. Ecol. Sociobiol. 22: 429-434.

Burness G.P., Diamond J. \& FlanNery T. 2001: Dinosaurs, dragons, and dwarfs: the evolution of maximal body size. Proc. Nat. Acad. Sci. USA 98: 14518-14523.

Cahan S.H., Blumstein D.T., Sundström L., Liebig J. \& GrifFIN A. 2002: Social trajectories and the evolution of social behavior. Oikos 96: 206-216.

Clark J.T. 1977: Aspects of variation in the stag beetle Lucanus cervus (L.) (Coleoptera: Lucanidae). Syst. Entomol. 2: 9-16.

Clutton-Brock T.H. 1991: The Evolution of Parental Care. Princeton University Press, Princeton, $368 \mathrm{pp}$.

Clutton-Brock T. \& Godfray C. 1991: Parental investment. In Krebs J.R. \& Davies N.B. (eds): Behavioural Ecology. 3rd ed. Blackwell Scientific, Oxford, pp. 234-262.

CRESPI B.J. 1992: Cannibalism and trophic eggs in subsocial and eusocial insects. In Elgar M.A. \& Crespi B.J. (eds): Cannibalism: Ecology and Evolution Among Diverse Taxa. Oxford University Press, New York, pp. 176-213.

Crespi B.J. \& Choe J.C. 1997: Explanation and evolution of social systems. In Choe J. \& Crespi B. (eds): The Evolution of Social Behavior in Insects and Arachnids. Cambridge University Press, Cambridge, pp. 499-524.

DANKS H.V. 2002: Modification of adverse conditions by insects. Oikos 99: 10-24. 
DARWIN C. 1871: The Descent of Man and Selection in Relation to Sex. John Murray, New York.

Eadie J.M., Kehoe F.P. \& Nudds T.D. 1988: Pre-hatch and posthatch brood amalgamation in North American Anatidae: a review of hypotheses. Can. J. Zool. 66: 1709-1721.

Eggert A.K., Reinking M. \& Müller J.K. 1998: Parental care improves offspring survival and growth in burying beetles. Anim. Behav. 55: 97-107.

Ento K., Araya K. \& Kudo S.I. 2008: Trophic egg provisioning in a passalid beetle (Coleoptera). Eur. J. Entomol. 105: 99-104.

Evans T.A. 1999: Kin recognition in a social spider. Proc. $R$. Soc. London (B) 266: 287-292.

Favila M.E. 1993: Some ecological factors affecting the lifestyle of Canthon cyanellus cyanellus (Coleoptera: Scarabaeidae): an experimental approach. Ethol. Ecol. Evol. 5: 319-328.

Fetherston I.A., Scott M.P. \& Traniello J.F.A. 1990: Parental care in burying beetles: the organization of male and female brood-care behavior. Ethology 85: 177-190.

GoDFray H.C.J. 1995: Evolutionary theory of parent offspring conflict. Nature 376: 133-138

Halffter G. 1997: Subsocial behavior in Scarabaeinae beetles. In Choe J. \& Crespi B. (eds): The Evolution of Social Behavior in Insects and Arachnids. Cambridge University Press, Cambridge, pp. 237-259.

Halffter G., Huerta C. \& López-Portillo J. 1996: Parental care and offspring survival in Copris incertus Say, a subsocial beetle. Anim. Behav. 52: 133-139.

Hayashi C. 1987: Lucanidae. The Insects of Japan. Series 8. Bun-ichi Sogo Press, Tokyo [in Japanese].

Harvey D.J. \& Gange A.C. 2006: Size variation and mating success in the stag beetle, Lucanus cervus. Physiol. Entomol. 31: $218-226$.

Hinton H.E. 1981: Biology of Insect Eggs. 3 Vols. Pergamon Press, Oxford, 1125 pp.

Hunt J., Simmons L.W. \& Kotiaho J.S. 2002: A cost of maternal care in the dung beetle Onthophagus taurus. J. Evol. Biol. 15: $57-64$.

JOHNSTON R.D. 1993: Effects of diet quality on the nestling growth of a wild insectivorous passerine, the house martin Delichon urbica. Funct. Ecol. 7: 255-266.

KAWANO K. 2000: Genera and allometry in the stag beetle family Lucanidae, Coleoptera. Ann. Entomol. Soc. Am. 93: 198-207.

KaLmBACH E. 2006: Why do goose parents adopt unrelated goslings? A review of hypotheses and empirical evidence, and new research questions. Ibis 148: 66-78.

Kent D.S. \& Simpson J.A. 1992: Eusociality in the beetle Austroplatypus incompertus (Coleoptera: Curculionidae). Naturwissenschaften 79: 86-87.

KING A. \& FASHING N. 2007: Infanticidal behavior in the subsocial beetle Odontotaenius disjunctus (Illiger) (Coleoptera: Passalidae). J. Insect Behav. 20: 527-536.

KirKendall L.R., Kent D.S. \& RafFa K.F. 1997: Interactions among males, females and offspring in bark and anbrosia beetles: the significance of living in tunnels for the evolution of social behavior. In Choe J. \& Crespi B. (eds): The Evolution of Social Behavior in Insects and Arachnids. Cambridge University Press, Cambridge, pp. 181-215.

MathieU J.M. 1969: Mating behavior of five species of Lucanidae (Coleoptera: Insecta). Can. Entomol. 101: $1054-1062$
Meek S.B. \& Robertson R.J. 1991: Adoption of young by replacement male birds: an experimental study of eastern bleubirds and a review. Anim. Behav. 42: 813-820.

Moreno J., Potti J. \& Merino S. 1997: Parental expenditure and offspring size in the pied flycatcher Ficedula hypoleuca. Oikos 79: 559-567.

OKadA Y. \& Hasegawa E. 2005: Size-dependent precopulatory behavior as mate-securing tactic in the Japanese stag beetle, Prosopocoilus inclinatus (Coleoptera; Lucanidae). J. Ethol. 23: $99-102$

Oksanen T.A., Alatalo R.V., Horne T.J., Koskela E., Mappes J. \& MAPPES T. 1999: Maternal effort and mate quality in the bank vole, Clethrionomys glareolus. Proc. R. Soc. Lond. (B) 266: 1495-1499.

Otте D. \& Stayman K. 1979: Beetle horns: some patterns in functional morphology. In Blum M.S. \& Blum N.A. (eds): Sexual Selection and Reproductive Competition in Insects. Academic Press, New York, pp. 259-292.

Pinheiro J. \& Bates D. 2002: Mixed Effects Models in $S$ and S-Plus. 3rd ed. Springer, New York, 528 pp.

Robert A.H. \& Slansky F. JR. 1985: Nutritional ecology of wood-feeding Coleoptera, Lepidoptera, and Hymenoptera. In Slansky F. Jr. \& Rodriguez J.E. (eds): Nutritional Ecology of Insects, Mites, Spiders, and Related Invertebrates WileyInterscience, New York, pp. 449-486.

R Development Core Team 2005: R: A Language and Environment for Statistical Computing. R Foundation for Statistical Computing. Vienna, Austria.

RIEDMAN M.L. 1982: The evolution of alloparental care and adoption in mammals and birds. Rev. Biol. 57: 405-435.

Rogowitz G.L. \& McCluRe P.A. 1995: Energy export and offspring growth during lactation in cotton rats (Sigmodon hispidus). Funct. Ecol. 9: 143-150.

SChUSTER J.C. \& Schuster L.B. 1997: The evolution of social behavior in Passalidae (Coleoptera). In Choe J. \& Crespi B. (eds): The Evolution of Social Behavior in Insects and Arachnids. Cambridge University Press, Cambridge, pp. 260-269.

ScOTT M.P. 1990: Brood guarding and the evolution of male parental care in burying beetles. Behav. Ecol. Sociobiol. 26: 31-39.

Sсотт M.P. 1994: The benefit of paternal assistance in intra- and interspecific competition in the burying beetle, Nicrophorus defodiens. Ethol. Ecol. Evol. 6: 537-543.

Sсотт M.P. 1997: Reproductive dominance and differential ovicide in the communally breeding burying beetle Nicrophorus tomentosus. Behav. Ecol. Sociobiol. 40: 313-320.

Sсотт M.P. 1998: The ecology and behavior of burying beetles. Annu. Rev. Entomol. 43: 595-618.

Tallamy D.W. 1984: Insect parental care. BioScience 34: $20-24$.

Tallamy D.W. \& Wood T.K. 1986: Convergence patterns in subsocial insects. Annu. Rev. Entomol. 31: 369-390.

Trumbo S.T. 1990: Reproductive benefits of infanticide in a biparental burying beetle Nicrophorus orbicollis. Behav. Ecol. Sociobiol. 27: 269-273.

VAlenZuela-GonZALEZ J.E. 1992: Adult-juvenile alimentary relationships in Passalidae (Coleoptera). Folia Entomol. Mex. 85: 25-37.

WATANUKI Y. 1992: Individual diet difference, parental care and reproductive success in slaty-backed gulls. Condor 94: 159-171.

Received October 7, 2008; revised and accepted January 19, 2009 